\title{
Mathematical and Mechanical Analysis of the Effect of Detonator Location and Its Improvement in Bench Blasting
}

\author{
Qidong Gao, ${ }^{1}$ Zhendong Leng $\mathbb{D},{ }^{2,3}$ Ruipeng Yang, ${ }^{1}$ Yaqiong Wang $\mathbb{D}^{1},{ }^{1}$ Ming Chen $\mathbb{D},{ }^{4}$ \\ Pengchang Sun, ${ }^{4}$ and Sheng $\mathrm{Luo}^{4}$ \\ ${ }^{1}$ School of Highway, Chang'an University, Xi'an 710064, China \\ ${ }^{2}$ Changjiang River Scientifc Research Institute, Wuhan 430010, China \\ ${ }^{3}$ Gezhouba Group Explosive Co., Ltd., Chongqing 401121, China \\ ${ }^{4}$ Key Laboratory of Rock Mechanics in Hydraulic Structural Engineering, Ministry of Education, Wuhan University, \\ Wuhan 430072, China \\ Correspondence should be addressed to Zhendong Leng; zdleng@whu.edu.cn and Yaqiong Wang; ys08@gl.chd.edu.cn
}

Received 10 October 2019; Revised 30 April 2020; Accepted 13 May 2020; Published 4 June 2020

Academic Editor: Arkadiusz Zak

Copyright (c) 2020 Qidong Gao et al. This is an open access article distributed under the Creative Commons Attribution License, which permits unrestricted use, distribution, and reproduction in any medium, provided the original work is properly cited.

\begin{abstract}
The outcome of bench blasting significantly affects the downstream operations in mining. In bench blasting, the explosives charged in blastholes are generally cylindrically shaped and fired by the in-hole detonator. As the detonator determines the propagation of the detonation wave in the cylindrical charge, the effect of detonator location can never be ignored. In this paper, the mathematics and mechanics of the effect of detonator location was analyzed from the view of the distribution of explosion energy and blast stress field of a cylindrical charge. Then, a field blasting experiment and two numerical simulations were conducted to further display its effect on blasting outcomes. At last, the appearance of oversize boulders and rock toes in bench blasting was discussed, and an improved scheme of the detonator location was proposed to cope with these problems. Results indicate that the in-hole detonator has the capacity of adjusting the spatial distribution of explosion energy and blast stress field in the surrounding rock mass. The traditional recommendation of the bottom detonator is not always right. The optimized detonator location in bench blasting is available by properly combining the merits of traditional detonator locations. This study is of interest to improve the efficiency and reduce the cost of mining.
\end{abstract}

\section{Introduction}

Blasting is generally the initial stage of rock breakage in mines, quarries, or geotechnical constructions, and its outcome plays a strong role in all downstream operations, such as loading, hauling, and crushing [1-4]. In practice, bench blasting is the most widely used operation pattern $[5,6]$. However, oversize boulders and rock toes that significantly affect the efficiency and cost of downstream operations often appear in the conventional bench blasting [7]. Hence, many studies devoting to achieving desired blasting outcomes can be witnessed in the past, see [8-12] for example. In bench blasting, the explosives charged in blastholes are usually cylindrically shaped and fired by the in-hole detonator. Due to the geometry characteristic and finite velocity of detonation (VOD), the detonation of the cylindrical charge exhibits directional and time effects [13]. Moreover, with the rapid advance in drilling machines, the blasting gradually develops to large-diameter and deep-hole blasting [7], where the directional and time effects are increasingly obvious. Therefore, the detonator location that determines the propagation of the detonation wave can never be ignored in bench blasting.

The previous studies related to the detonator location mainly focused on the rock fragmentation and blast stress field. Long et al. [14] investigated the effect of detonator location on the rock fragmentation outcome in iron mine, based on the analysis of the usage ratio of explosive energy. Zhang [15] tried to increase the ore extraction by changing the detonator location and conducted many field verification 
experiments in LKAB Malmberget mine in Sweden. Onederra et al. discovered that the rock damage degree at the top section is relatively larger if the detonator is placed at the hole bottom, when using the HSBM (Hybrid Stress Blasting Model) method to simulate blasting [16]. Liu et al. [17] studied the effect of detonator location on boulders and rock toes in bench blasting via the numerical simulation and blasting practice. Leng et al. [18] discussed the nonideal detonation reaction at the primary initiation stage of the explosive and compared the rock fragmentation outcomes between side-initiation and end-initiation. Unlike the spherical charge where the source radiation is the same in all directions [19], the radiation pattern of the cylindrical charge is uniform. The typical investigation of the radiation pattern of a column explosive source is the work by Heelan [20]. He derived the displacement solution of a short column cavity, and the result indicates that the P-and SV-waves are simultaneously beamed out from the explosive source and channeled in certain directions [20]. Afterwards, Jordan, Abo-zena, and White also discussed the radiation pattern of a short column explosive source [21-23]. The blast stress field of an extended cylindrical charge can be approximated by summing the contributions of the short element charges along the entire length [24]. Many related investigations show that the amplitude of the blast stress or vibration of a cylindrical charge exists directional effect, i.e., the amplitudes at the forward direction of the detonation wave are higher than those at the backward direction, such as the works by Gong, Vanbrabant, Triviño, and Liu [25-28].

As illustrated in Figure 1, the detonators were traditionally placed at the top, bottom, or midpoint sections of the explosive charge. Beyond that, as the blastholes tend to deepen, two detonators are simultaneously employed to prevent misfires of the explosive in practice. By considering the acting time of gaseous products, most previous researchers recommended the bottom detonator location [14]. However, they ignored the effect of detonator location on the spatial distribution of explosion energy transmitted into the surrounding rock mass. The existing studies have displayed a part of the effect of the detonator location, but its underlying acting mechanism is still not well explained. The current understanding of the detonator location is not enough for the rapid developing requirements of blasting. It is thus necessary to further analyze the mathematics and mechanics of the effect of detonator location on blasting outcomes.

This paper aims to enhance the understanding of the effect of detonator location in bench blasting, so as to improve the outcome of bench blasting. It is divided into three main sections: the theoretical analysis, the experimental and numerical verification, and the proposed improvement of detonator location. In the first section, the effect of detonator location was analyzed both mathematically and mechanically from the point of the distribution of explosion energy and blast stress field of a cylindrical charge. Then, a singlehole blasting experiment as well as two numerical simulations was further implemented to display the effect of detonator location on blasting outcomes. At last, problems of the oversize boulders and rock toes faced in bench blasting were discussed, and an improved scheme of detonator
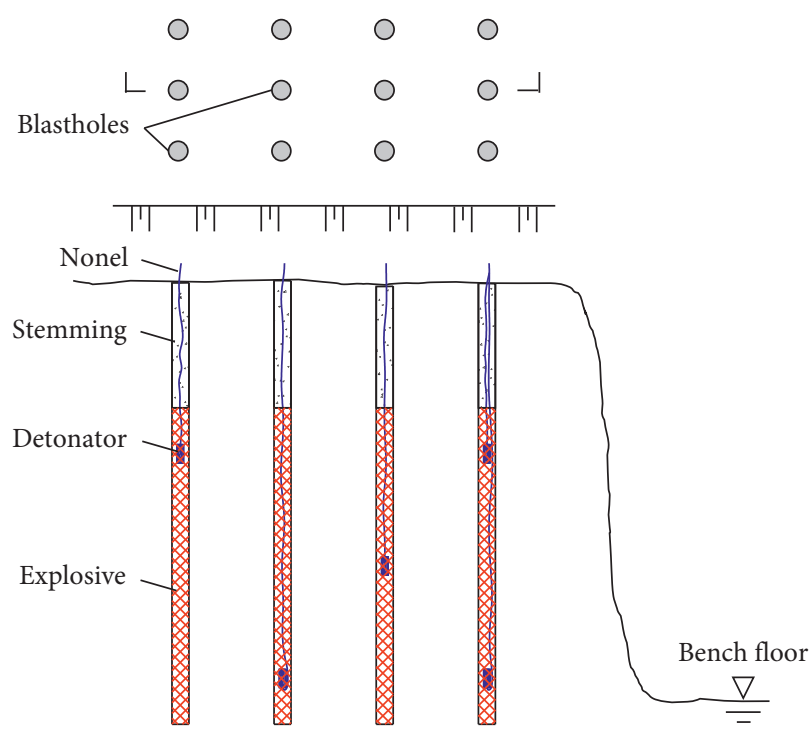

(a) (b)

(c)

(d)

FIgURE 1: Illustration of the traditional detonation locations in bench blasting. (a) Top detonator; (b) Bottom detonator; (c) Midpoint detonator; (d) Top-bottom detonators.

location was proposed based on the idea of combining the merits of top and bottom detonator locations. This study is of interest to improve the efficiency and profit in mining.

\section{Mathematical and Mechanical Analysis of the Effect of Detonator Location}

2.1. Effect of Detonator Location on Energy Distribution. In bench blasting, the explosives charged in blastholes are cylindrically shaped. It is well accepted that the explosive detonation is a complex chemical reaction process along with the chemical energy transforming to the internal and kinetic energy of the detonation products. Based on the Chapman-Jouguet theory, Figure 2 illustrates the detonation reaction of the explosive and the propagation of the detonation wave. For the cylindrical charge, the detonation reaction exhibits time and directional effects along the entire length [13]. Consequently, the distribution of the detonation products and explosion energy is inevitably affected by the location of the firing point (the detonator location in practice).

To simplify the problem, the one-dimensional flow model, assuming that the cylindrical charge is placed in a vacuum rigid pipe [29], was used to analyze the distribution of detonation products and explosion energy. As plotted in Figure 3 , the length of the charge is defined as $l$, and the lengths at the left and right sides of the firing point are, respectively, $b$ and $a$. The initial density and detonation velocity are, respectively, $\rho_{0}$ and $V_{0}$, and the cross section area of the explosive is $S$. The steady detonation velocity is denoted by $V$.

Firstly, the motion law of detonation products is expressed as equation (1) assuming that the detonation products are isentropic: 


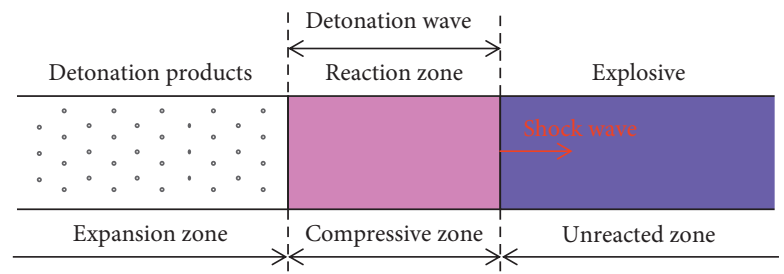

FIgURE 2: Illustration of the detonation reaction of explosive.

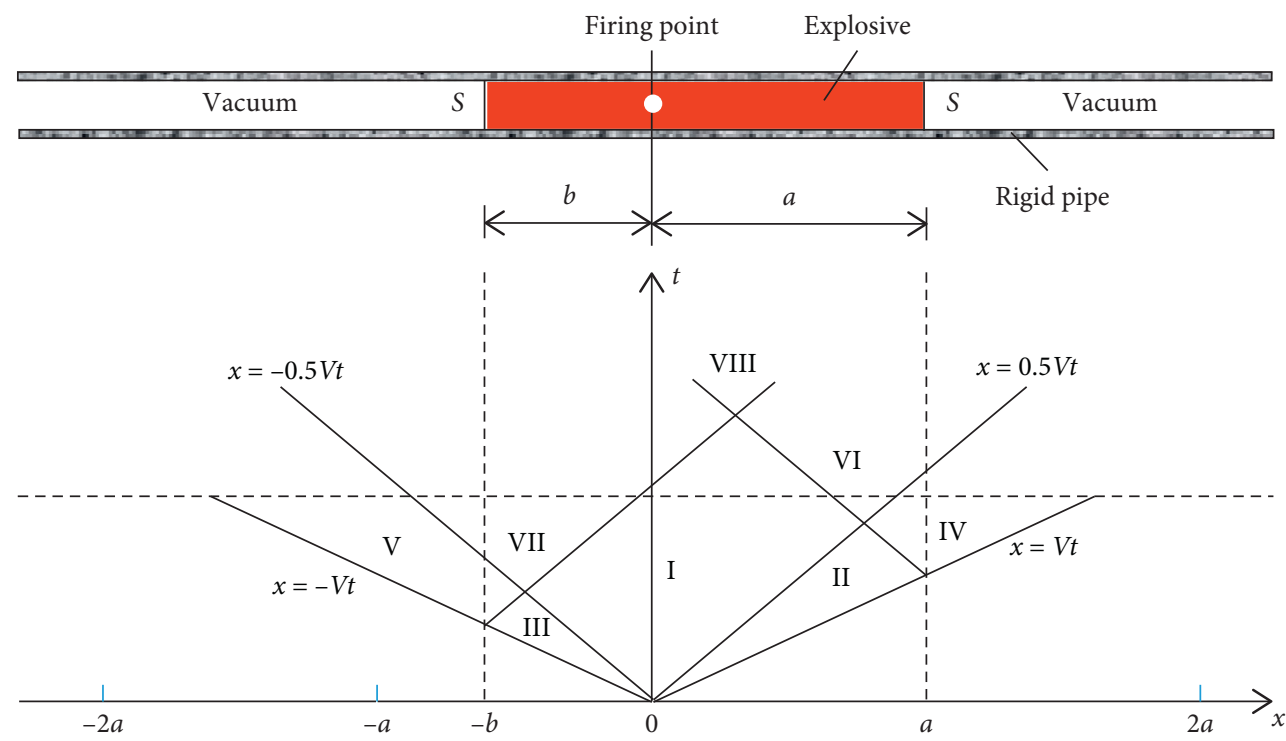

Figure 3: One-dimensional flow model of the detonation of a cylindrical charge.

$$
\frac{\partial}{\partial t}\left(u \pm \frac{2}{\gamma-1} c\right)+(u \pm c) \frac{\partial}{\partial x}\left(u \pm \frac{2}{\gamma-1} c\right)=0
$$

where $u$ is the particle velocity of detonation products, $c$ is the local sonic velocity, $\gamma$ is the adiabatic exponent, and + and -, respectively, denote the left and right propagation waves. If setting $\gamma=3$, as is rational for most condensed explosives, equation (1) can be simplified as

$$
\frac{\partial}{\partial t}(u \pm c)+(u \pm c) \frac{\partial}{\partial x}(u \pm c)=0
$$

Then, the characteristic line of the motion equation is solved as

$$
\left\{\begin{array}{l}
x=(u \pm c) t+B \\
(u \pm c)=\text { const }
\end{array}\right.
$$

where $B$ is the integration constant. As illustrated in Figure 3, the shock wave and the rarefaction wave will simultaneously propagate to the left and right sides once the explosive is fired. It can be solved from equation (3) that, for the right propagation case (the charge is fired at the left end), the velocity of the shock wave and rarefaction wave propagating to the right side is $-V$, while the velocity of the rarefaction wave propagating to the left side is $+V / 2$. Similarly, for the left propagation case (the charge is fired at the right end), the velocity of the shock wave and rarefaction wave propagating to the left side is $+V$, while the velocity the rarefaction wave propagating to the right side is $-V / 2$. Hence, the motion track of detonation products is a group of parallel lines, as expressed in the following equation:

$$
\left\{\begin{array}{l}
x= \pm V t \\
x= \pm \frac{1}{2} V t .
\end{array}\right.
$$

As illustrated in Figure 3, there are altogether eight different kinds of flow fields appearing in the pipe. They are, respectively, the static zone I, the rightwards simple wave zone II, the leftwards simple wave zone III, the right complex wave zone IV, the left complex wave zone $\mathrm{V}$, the rightwards simple wave zone VI, the leftwards simple wave zone VII, and the middle complex wave zone VIII. Table 1 lists the time-space solutions of the motion equation in different flow fields [29].

After sufficient time, only five flow fields (IV VIII) are remained, with the three (IV, VI, and VIII) of them distributed at the right side and the other three (V, VII, and VIII) distributed at the left side. By substituting the timespace solutions $u$ and $c$ (refer to Table 1 ) into equation (5), the mass and energy of detonation products flowing into the left and right sides can be computed by the following equations: 
TABle 1: Time-space solutions of the motion equation in different flow fields [29].

\begin{tabular}{|c|c|c|c|}
\hline Flow field no. & Time-space solution & Flow field no. & Time-space solution \\
\hline I & $\left\{\begin{array}{l}u=0 \\
c=(1 / 2) V\end{array}\right.$ & $\mathrm{V}$ & $\left\{\begin{array}{l}u=(1 / 2)((x / t)+((x+b) /(t-b / V))) \\
c=(1 / 2)((x / t)-((x+b) /(t-b / V)))\end{array}\right.$ \\
\hline II & $\left\{\begin{array}{l}u=(1 / 2)(x / t-(1 / 2) V) \\
c=(1 / 2)(x / t+(1 / 2) V)\end{array}\right.$ & VI & $\left\{\begin{array}{l}u=(1 / 2)((1 / 2) V+((x-a) /(t-a / V))) \\
c=(1 / 2)((1 / 2) V-((x-a) /(t-a / V)))\end{array}\right.$ \\
\hline III & $\left\{\begin{array}{l}u=(1 / 2)((x / t)+((1 / 2) V)) \\
c=(1 / 2)(((1 / 2) V)-(x / t))\end{array}\right.$ & VII & $\left\{\begin{array}{l}u=(1 / 2)((-(1 / 2) V)+((x+a) /(t-b / V))) \\
c=(1 / 2)((1 / 2) V-((x+a) /(t-b / V)))\end{array}\right.$ \\
\hline IV & $\left\{\begin{array}{l}u=(1 / 2)((x / t)+((x-a) / t-(a / V))) \\
c=(1 / 2)((x / t)-((x-a) / t-(a / V)))\end{array}\right.$ & VIII & $\left\{\begin{array}{l}u=(1 / 2)(((x+b) /(t-b / V))+((x-a) /(t-a / V))) \\
c=(1 / 2)(((x+b) /(t-b / V))-((x-a) /(t-a / V)))\end{array}\right.$ \\
\hline
\end{tabular}

$$
\begin{aligned}
& \left\{\begin{array}{l}
M=A \int \rho \mathrm{d} x=\frac{16 \rho_{0}}{9 V} A \int \rho \mathrm{d} x, \\
E=\frac{1}{2} A \int \rho u^{2} \mathrm{~d} x=\frac{8 \rho_{0}}{9 V} A \int c u^{2} \mathrm{~d} x,
\end{array}\right. \\
& \left\{\begin{array}{l}
M_{b}=\frac{1}{9} \rho_{0} A(4 a+5 b), \\
M_{a}=\frac{1}{9} \rho_{0} A(5 a+4 b), \\
E_{b}=\frac{1}{27} \rho_{0} S V^{2}\left(\frac{11}{16} a+b\right), \\
E_{a}=\frac{1}{27} \rho_{0} S V^{2}\left(a+\frac{11}{16} b\right),
\end{array}\right.
\end{aligned}
$$

where $M$ and $E$ are, respectively, the mass and energy of detonation products, and the subscripts $b$ and $a$, respectively, denote the mass and energy distributed to the left and right sides. For a special case, assuming that $b=0$ and $a=l$ (the charge is fired at the left end), equations (6) and (7) can be further simplified as

$$
\begin{gathered}
\left\{\begin{array}{c}
M_{b}=\frac{4}{9} \rho_{0} S l, \\
M_{a}=\frac{5}{9} \rho_{0} S l,
\end{array}\right. \\
\left\{\begin{array}{l}
E_{b}=\frac{11}{27} \frac{l}{16} \rho_{0} S V^{2}, \\
E_{a}=\frac{16}{27} \frac{l}{16} \rho_{0} S V^{2} .
\end{array}\right.
\end{gathered}
$$

Equations (6) and (7) indicate that the distribution of detonation energy is closely associated with the parameters $b$ and $a$, i.e., the location of the firing point. It can be concluded from equations (8) and (9) that more detonation products and energy are distributed to the forward direction of the detonation wave. If the cylindrical charge is fired at the left end, the mass of detonation products and the energy distributed to the right side is, respectively, 1.25 and 1.45 times of those distributed to the left side. It has to be clarified that the practical blasting is much more complicated than the one-dimensional model. However, the above analysis revealed that the detonator location plays a significant role in the energy distribution of a cylindrical charge.

2.2. Effect of Detonator Location on Blast Stress Field. The blast stress field of a cylindrical charge is usually approximated by summing the contributions of the short element charges along the entire length [24], as shown Figure 4. The total length of the charge is defined as $l$, and it is divided into $n$ short element charges. As the explosive velocity of detonation is not infinite high and exhibits as the same level of the sonic velocity of rock mass, the phase delay effect between the element charges cannot be ignored. Taking the bottom detonator case as an example (see Figure 4), the source radiation from the element charge $(i-1)$ is $l / n V$ earlier than the element charge $i$. For the observation point $P$ that is located at the top side, the stress amplitudes of the subsequent element charges become larger and larger, for the subsequent element charges are closer to the observation point. On the contrary, the contributions from the subsequent charge elements for the point $Q$ located at the bottom side become weaker and weaker. It is not hard to conclude that the blast stress field of a cylindrical charge is also strengthened at the forward direction of the detonation wave.

In this computation model, if supposing that the source of the element charge is spherically radiated, the source function can be described as [28]

$$
f(R, t)= \begin{cases}A R^{-\alpha} g(t-\tau), & t \geq \tau, \\ 0, & t<\tau,\end{cases}
$$

where $A R^{-\alpha}$ is the amplitude of the stress wave at the distance $R$ and shows an attention of $R^{-\alpha}, g(t)$ describes the wave shape of the element charge, and $\tau$ is the travel time of the stress wave from each element charge to the observation point. The wave shape here is described by a damped sine wave, as expressed in the following equation:

$$
g(t)=e^{-\beta t} \sin (\omega t),
$$

where $\beta$ and $\omega$ are, respectively, the damping coefficient and angular frequency. Then, the total blast stress solution $F(r, z, t)$ can be computed by 


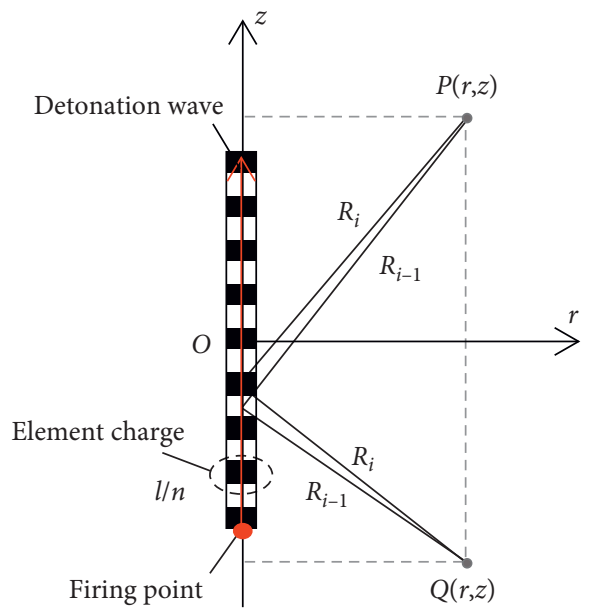

Figure 4: Computation model of the blast stress field of a cylindrical charge.

$$
\left\{\begin{array}{l}
F_{r}=\sum f \sin \varphi_{i}, \sin \varphi_{i}=\frac{r}{R_{i}}, \\
F_{z}=-\sum f \cos \varphi_{i}, \cos \varphi_{i}=\frac{z-(i-1 / 2) l / n+l / 2}{R_{i}} .
\end{array}\right.
$$

The travel time $\tau_{i}$ and distance $R_{i}$ of each element charge can be written as

$$
\left\{\begin{array}{l}
\tau_{i}=\frac{R_{i}}{C}+\frac{(i-1 / 2) l}{n V}, \\
R_{i}=\sqrt{r^{2}+\left(z-\frac{(i-1 / 2) l}{n}+\frac{l}{2}\right)^{2}},
\end{array}\right.
$$

where $C$ is the sonic velocity of rock mass.

Figure 5 plots the contour line of the peak blast stress of the cylindrical charge that is fired at the bottom. It indicates that the blast stress field of a cylindrical charge is not uniformly distributed but strengthened at the top side. The blast stress at the top side is 38\% larger than that at the bottom side. It needs to be pointed that although the source of the short explosive column is actually not spherically radiated, the mathematical analysis in Figure 5 helps revealing the effect of detonator location on the distribution of blast stress field.

In summary, the effect of detonator location can be interpreted as the following two points. On the one hand, the energy distribution of a cylindrical charge is closely associated with the detonator location and more energy is distributed to the forward direction of the detonation wave. On the other hand, due to the phase delay effect, the blast stress of a cylindrical charge is not uniformly distributed but strengthened at the forward direction of the detonation wave either. The underlying effect is that the detonator determines the propagation of the detonation wave and thereby has the capacity of adjusting the distribution of explosion energy and blast stress field.

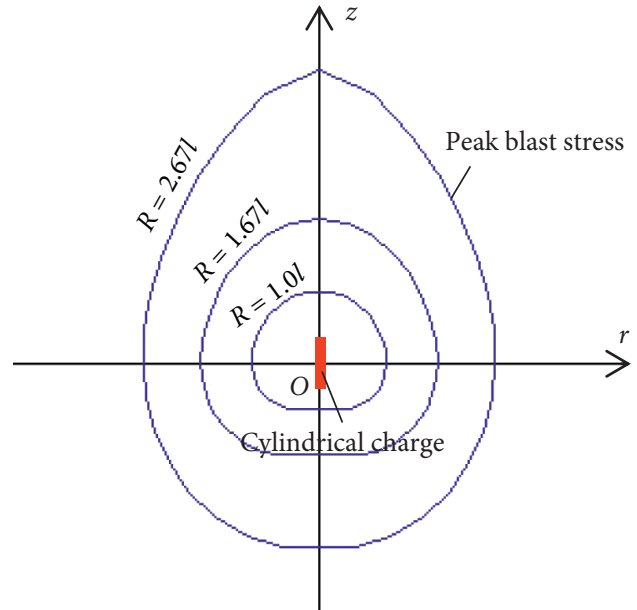

Figure 5: Contour line of the peak blast stress of the cylindrical charge that is fired at the bottom. The peak stress is represented by the normalized distance from $(O)$ in the polar coordinate system.

\section{Experimental Verification of the Effect of Detonator Location}

3.1. Experiment Design. To verify the effect of detonator location, a single-hole blasting experiment was conducted during the foundation excavation of a hydropower station. As shown in Figure 6, four vertical blastholes were set at the square corners. The length of the square was $3.5 \mathrm{~m}$, and all the blastholes were $6.0 \mathrm{~m}$ in depth and $100 \mathrm{~mm}$ in diameter. The explosive adopted was $2 \#$ rock emulsion, and the charge length was $4.5 \mathrm{~m}$ and $32 \mathrm{~mm}$ in diameter. The detailed drill and blast parameters are listed in Table 2.

All the blastholes were fired in the same blasting network (see Figure 7), and the nonelectric millisecond (MS) detonator was used to separate each shot. The delay time was, respectively, MS1 (0 ms), MS5 (110 ms), MS9 $(310 \mathrm{~ms})$, and MS13 (650 ms). As plotted in Figure 8, the detonators in blastholes $A$ and $B$ were placed at the top section of the explosive, while those in blastholes $C$ and $D$ were placed at the bottom section. It should be pointed that the iron balls were placed at the bottom of blastholes $A$ and $C$. In addition, the coupling medium between the explosive and rock mass is rock debris. The design of iron balls is beyond the scope of this study, and the detailed introduction refers to $\mathrm{Hu}$ et al. $[30,31]$. In fact, this is a combined experiment, but it does not affect the contrast groups, i.e., boreholes $A$ versus $C$ and boreholes $B$ versus $D$.

As illustrated in Figure 9, three uniaxial vibration sensors (CDJ28) were installed in the monitoring hole. They were, respectively, $1.0 \mathrm{~m}, 1.5 \mathrm{~m}$, and $2.0 \mathrm{~m}$ below the blasthole bottom. It needs to be pointed that the vibration sensors were fixed on a bamboo slip in advance and then placed into the monitoring hole and coupled with the rock mass using cement slurry. The instrument TC-4850, made by Chengdu Zhongke Measurement and Control Ltd., China, was used to record the blast vibration signal. It measures velocity and has a wide range of $0.001 \sim 35.4 \mathrm{~cm} / \mathrm{s}$. 


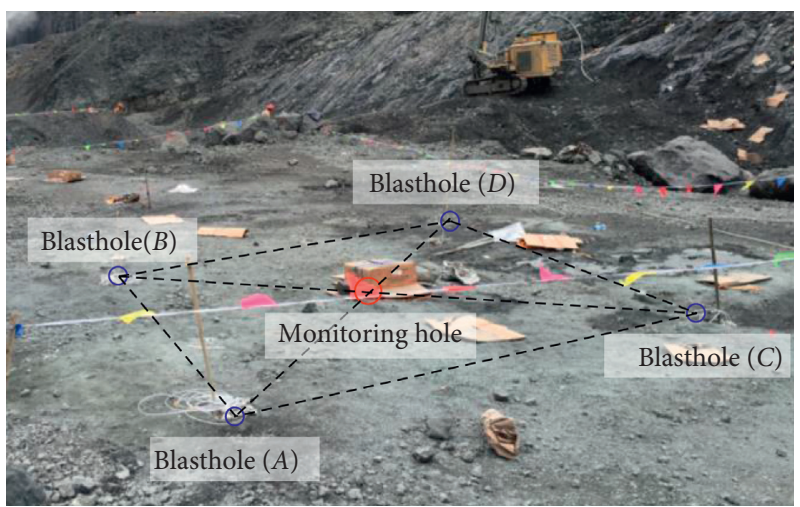

FIgURE 6: Onsite layout of the blastholes and monitoring hole.

TABle 2: Drill and blast parameters in the field experiment.

\begin{tabular}{lccccc}
\hline Hole diameter $(\mathrm{mm})$ & Hole depth $(\mathrm{m})$ & Spacing $(\mathrm{m})$ & Charge diameter $(\mathrm{mm})$ & Charge length $(\mathrm{m})$ & Charge weight $(\mathrm{kg})$ \\
\hline 100 & 6.0 & 3.5 & 32 & 4.5 & 4.5 \\
\hline
\end{tabular}

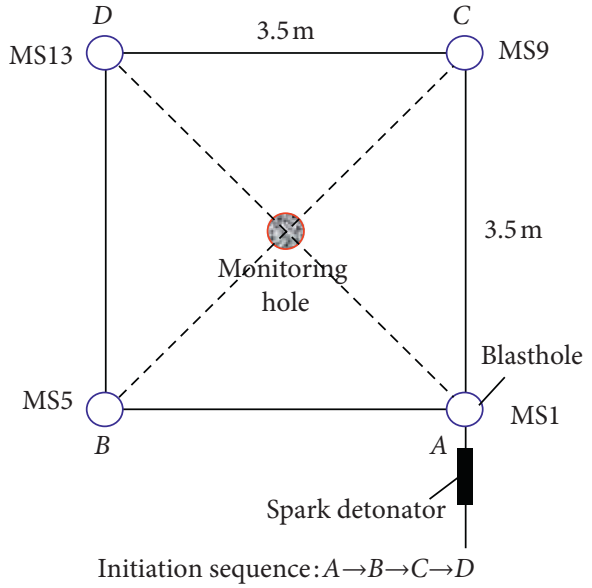

Figure 7: Initiation sequence of the blastholes in the field experiment.

The sampling rate was taken as $125 \mu$ s, i.e., recording 8000 samples per second. It begins recoding ( $5 \mathrm{~s}$ duration with $0.1 \sim 0.2 \mathrm{~s}$ of pretrigger) when the particle velocity exceeds the preset threshold $(0.10 \mathrm{~cm} / \mathrm{s})$. Figure 10 presents the blast vibration monitoring system adopted in the field experiment.

3.2. Test Results. Figure 11 presents the pictures of rock mass after blasting. It shows that the features of the rock mass of the four blastholes are quite different. For blastholes $A$ and $B$, where the detonator is placed at the top section, only slight heave movement of the rock mass can be witnessed along with the formation of few blasting cracks. However, visible blasting craters are formed and many rock fragments are thrown outwards for blastholes $C$ and $D$, where the detonator is located at the hole bottom. Moreover, the rock mass for

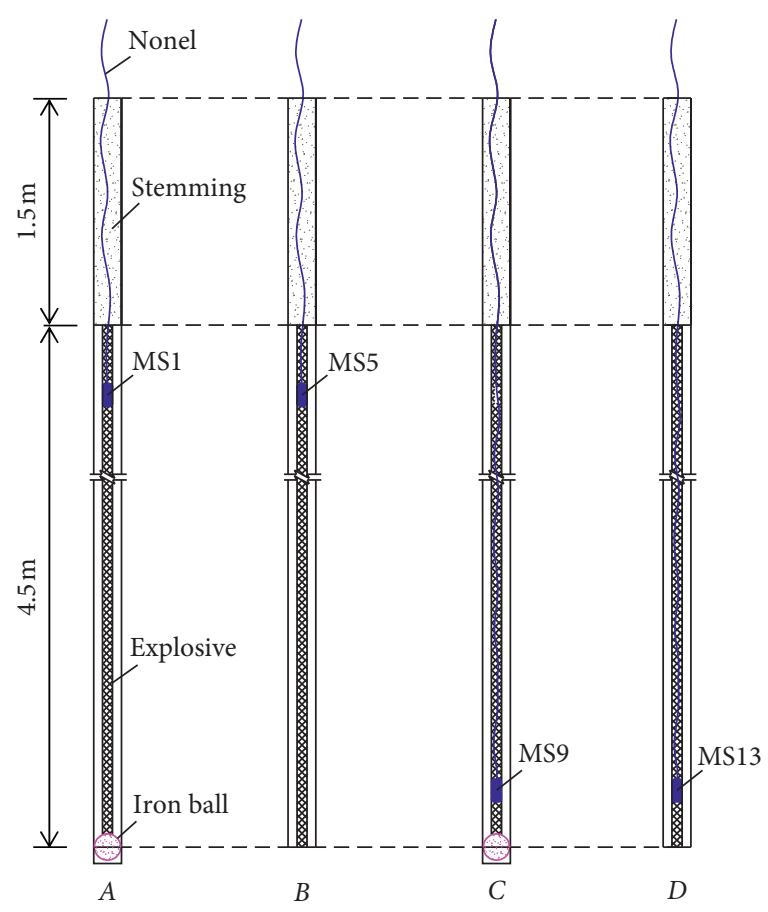

FIgURE 8: Charging structures in the field experiment.

blastholes $C$ and $D$ is darker than that for blastholes $A$ and $B$ because the rock mass with higher humidity surrounding blastholes $C$ and $D$ is lifted out by the upwards transmitting explosion energy. Obviously, more explosion energy is transmitted upwards if the detonator is located at the bottom section. Figure 11 provides a solid evidence on the effect of detonator location on the distribution of explosion energy.

Figure 12 plots the typical velocity time-history recorded by the \#2 vibration senor, which contains four evident signals that are separated at the time axis. They are, 


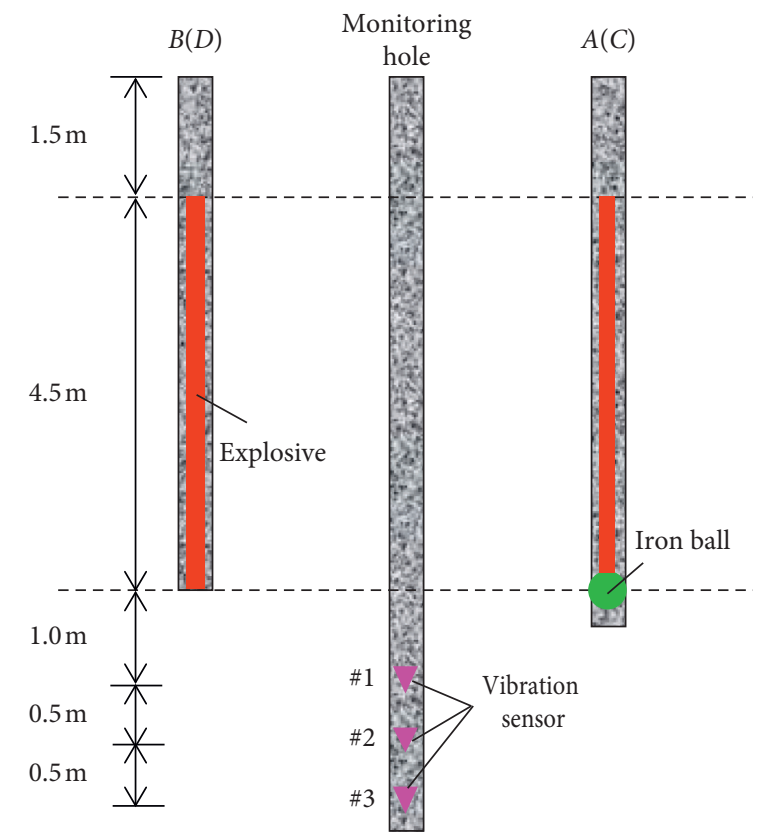

Figure 9: Layout of the uniaxial vibration sensors installed in the monitoring hole.

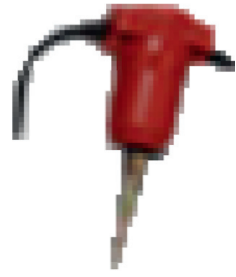

(a)

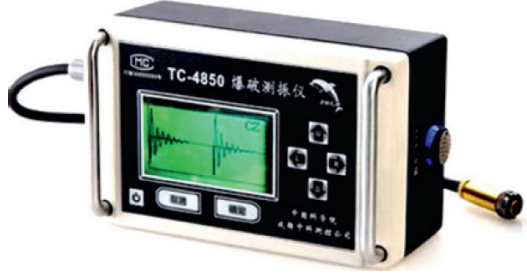

(b)

FIGURE 10: Intelligent blast vibration monitoring system. (a) Uniaxial vibration sensor CDJ28; (b) recording instrument TC-4850.

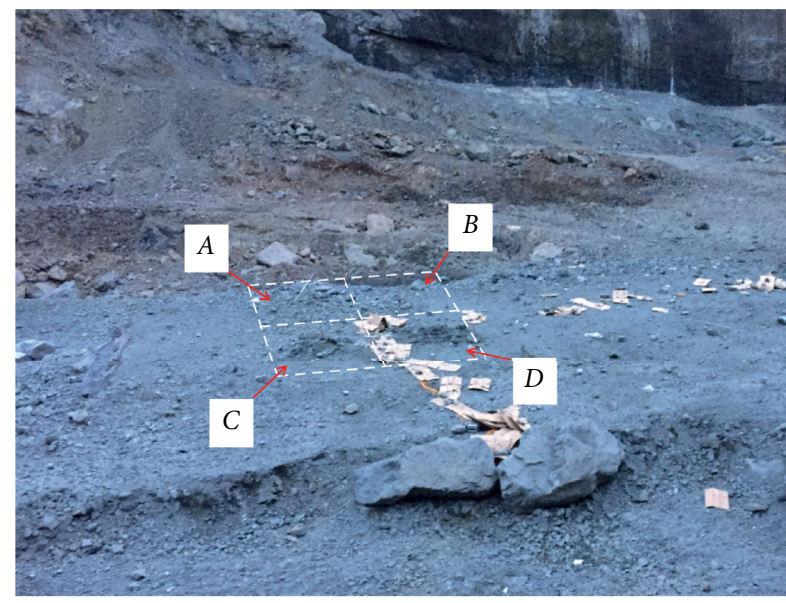

(a)
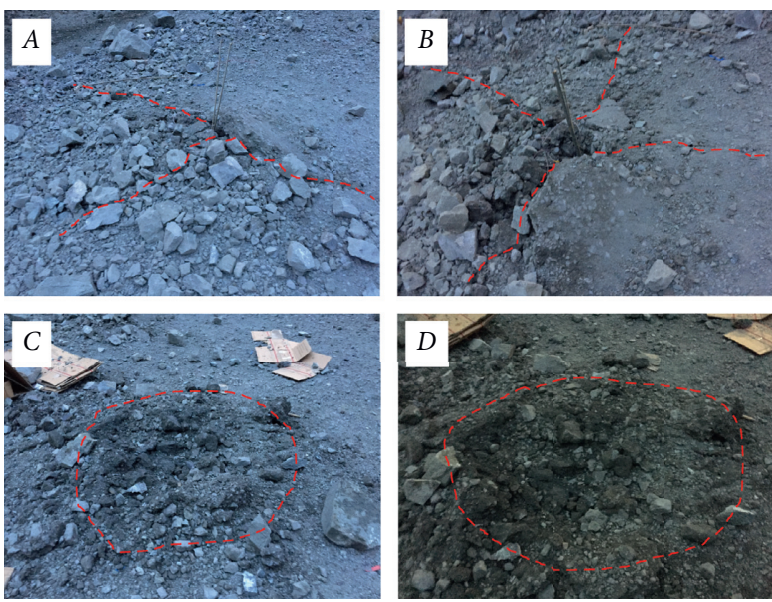

(b)

FIgURe 11: Pictures of the rock mass after blasting. (a) Overall picture; (b) local pictures.

respectively, the blast vibration induced by blastholes $A \sim D$. Table 3 lists the peak particle velocities (PPVs), and Figure 13 illustrates the comparison of PPVs according to the designed contrast groups.
The contrast groups in Figure 13 indicate that the amplitude of blast vibration is closely associated with the detonator location. The PPVs under the bottom detonator (blastholes $C$ and $D$ ) are $21.0 \% \sim 59 \%$ smaller than those 


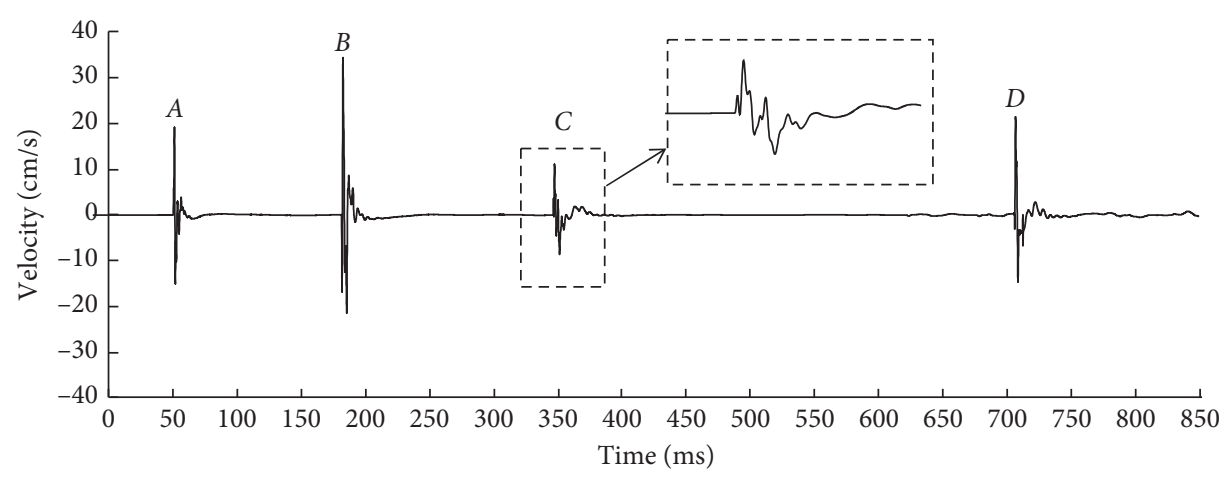

Figure 12: Typical velocity time-history recorded in the field experiment.

Table 3: Measured PPVs in the field experiment.

\begin{tabular}{|c|c|c|c|c|}
\hline \multirow{2}{*}{ Sensor no. } & \multicolumn{4}{|c|}{$\mathrm{PPV}(\mathrm{cm} / \mathrm{s})$} \\
\hline & Blasthole $A$ & Blasthole $B$ & Blasthole $C$ & Blasthole $D$ \\
\hline$\# 1$ & 18.37 & 32.50 & 14.51 & - \\
\hline$\# 2$ & 19.21 & 34.40 & 11.09 & 21.47 \\
\hline$\# 3$ & 19.33 & 27.55 & 7.92 & 14.07 \\
\hline
\end{tabular}

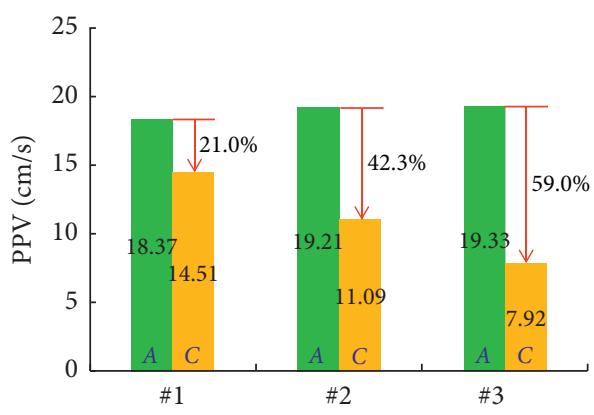

(a)

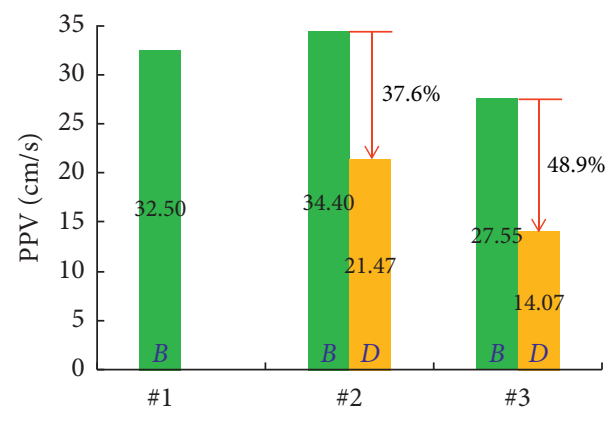

(b)

Figure 13: Comparison of PPVs under differing detonator locations. (a) Blastholes with iron balls (blastholes A vesus C); (b) blastholes without iron balls (blastholes B vesus D).

under the top detonator (blastholes $A$ and $B$ ). The test results demonstrate that the blast vibration at the forward direction of the detonation wave is larger than that at the backward direction. This should be attributed to the combined results of the effect of detonator location on the distribution of explosion energy and blast stress field, as was analyzed in Section. 2.

\section{Numerical Simulation of the Effect of Detonator Location}

As was stated above, the mathematics and mechanics analysis and the experimental results both indicate that the detonator location plays an important role in the distribution of explosion energy and blast stress field. However, its effect on rock fragmentation is still not well displayed. Therefore, based on the widely used LS-DYNA program, the effect of detonator location is further investigated in this section.

\subsection{Damage Distribution of a Single Cylindrical Charge}

4.1.1. Model and Parameters. As illustrated in Figure 14, a three-dimensional model was developed to reproduce the blasting of a cylindrical charge in the infinite rock mass. Only a quarter of the cuboid was constructed according to the symmetric property of the problem. The model dimension is $5.0 \mathrm{~m} \times 5.0 \mathrm{~m} \times 10.0 \mathrm{~m}$ (length $\times$ width $\times$ height), and it contains 38, 902 elements and 46, 625 nodes. Except for the symmetric boundaries, the nonreflecting boundaries were applied to all the other sides of the model to eliminate the boundary reflection.

The cylindrical charge is $3 \mathrm{~m}$ in length and $32 \mathrm{~mm}$ in diameter. The widely used Jones-Wilkens-Lee (JWL) equation of state was used to simulate the detonation of explosive, as expressed in the following equation:

$$
P=A\left(1-\frac{\omega}{R_{1} V}\right) e^{-R_{1} V}+B\left(1-\frac{\omega}{R_{2} V}\right) e^{-R_{2} V}+\frac{\omega E}{V},
$$




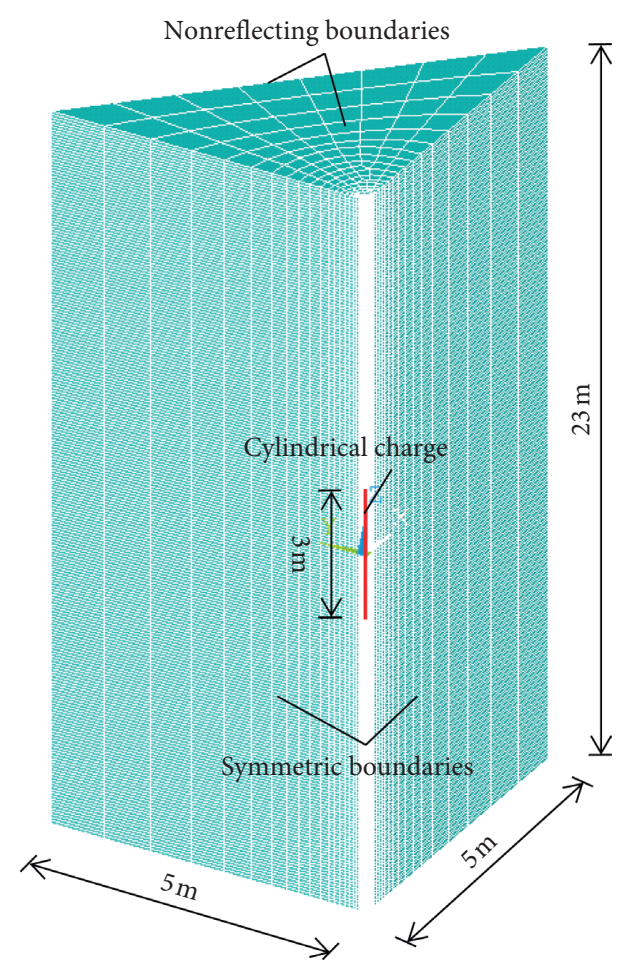

FIGURE 14: Numerical model of the blasting of a cylindrical charge in the infinite rock mass.

where $P$ is the detonation pressure, $V$ is the relative volume of detonation products, $E$ is the internal energy with an initial value of $E_{0}$, and $A, B, R_{1}, R_{2}$, and $\omega$ are the parameters related to explosive types. The explosive adopted was the \#2 rock emulsion, and its JWL parameters refer to $\mathrm{Li}$ et al. [32], as listed in Table 4, where VOD is the explosive velocity of the detonator, and PCJ is the Chapman-Jouguet pressure.

In recent years, with the rapid development of simulation techniques, various kinds of constitutive models were developed to record the mechanic behavior of rock mass [33]. Lu et al. [34, 35] developed a user-defined model that incorporates the compressive damage into the existing tensile damage model to simulate the rock damage during blasting. This model is named as the tensile-compressive damage model and has shown its outstanding ability in revealing the mechanic behavior of rock mass near the blasthole. It is thus also adopted in the present numerical simulation. The detailed introduction and establishment of this model refers the work of $\mathrm{Lu}$ et al. [34, 35].

The core of this model is that it comprehensively accounts for the tensile and compressive damage, as expressed in the following equations:

$$
\begin{aligned}
D_{t} & =\frac{16}{9} \frac{\left(1-\bar{\mu}^{2}\right)}{(1-2 \bar{\mu})} C_{d}, \\
D_{c} & =\frac{\lambda \dot{W}_{p}}{1-D_{t}}, \\
D & =\max \left(D_{t}, D_{c}\right),
\end{aligned}
$$

where $D_{t}$ and $D_{c}$ are, respectively, the tensile and compressive damage scalars, $\bar{\mu}$ is the degraded Poisson's ratio, and $C_{d}$ is the crack density, $\lambda$ is the damage sensitivity coefficient, $\dot{W}_{p}$ is the plastic power rate, and $D$ is the unified scalar that describes the most unfavorable factors of tensile and compressive damage. Then, the degraded bulk modulus $\bar{K}$ and shear modulus $\bar{G}$ can be written as

$$
\left\{\begin{array}{l}
\bar{K}=K(1-D), \\
\bar{G}=\frac{3(1-2 \bar{\mu})}{2(1+\bar{\mu})} \bar{K} .
\end{array}\right.
$$

Subsequently, the constitutive law could be described as the form of the increment Hooke's law, as expressed in the following equation:

$$
d \sigma_{i j}=\bar{K} d \varepsilon_{k k} \delta_{i j}+2 \bar{G} d e_{i j}
$$

where $\varepsilon_{k k}$ and $e_{i j}$ are, respectively, the volumetric and deviatoric strains and $\delta_{i j}$ is the Kronecker delta function. Using the user subroutine interface in the LS-DYNA software, the code of the above constitutive law can be inserted into the source program. Table 5 lists the corresponding physical parameters of rock mass in the computation, where KIC is the fracture toughness of the material and $k$ and $m$ are the damage coefficients.

4.1.2. Numerical Results. Three different calculation conditions, including the bottom detonator, midpoint detonator, and two-end detonators were completed by the above numerical model. Figure 15 gives the blast-induced damage distribution of the cylindrical charge under differing detonator locations. It indicates that the damage of the cylindrical charge is not uniformly distributed and controlled by the detonator location. For the bottom detonator case, the damage preferentially develops to the top side and the damage radius at the top-end section is 2.5 times of that at the bottom-end section (see Figure 15(a)), whereas the detonation waves under the midpoint and two-end detonator cases simultaneously propagate to the two ends or midpoint of the charge. Therefore, for the midpoint detonator case (see Figure 15(b)), the damage radius at the twoend section is 1.4 times of that at the middle section, while for the two-end detonator case (see Figure 15(c)), the damage radius at the middle section is 3.0 times of that at the two-end section. It is not hard to say that the blast-induced damage preferentially develops to the forward direction of the detonation wave. The simulation of the cylindrical charge helps in visually displaying the effect of detonator location on blasting outcomes.

\subsection{Simulation of the Multihole Blasting}

4.2.1. Model and Parameters. To further compare the rock fragmentation effects under differing detonator locations, another three-dimensional model was developed to simulate a simple multihole blasting. As shown in Figure 16, the model dimension is $15.4 \mathrm{~m} \times 6.8 \mathrm{~m} \times 10.0 \mathrm{~m}$ 
TABLE 4: Jones-Wilkens-Lee (JWL) parameters of the explosive.

\begin{tabular}{lccccccc}
\hline Density $\left(\mathrm{kg} / \mathrm{m}^{3}\right)$ & VOD $(\mathrm{m} / \mathrm{s})$ & PCJ $(\mathrm{GPa})$ & $A(\mathrm{GPa})$ & $B(\mathrm{GPa})$ & $R_{1}$ & $R_{2}$ & $\omega$ \\
\hline 1000 & 3600 & 3.24 & 220 & 0.2 & 4.5 & 1.1 & 0.35 \\
\hline
\end{tabular}

TABLE 5: Physical parameters of rock mass in the numerical simulation.

\begin{tabular}{lcccccc}
\hline \multirow{2}{*}{ Density $\left(\mathrm{kg} / \mathrm{m}^{3}\right)$} & Elastic modulus $(\mathrm{GPa})$ & Poisson's ratio & Tensile intensity $(\mathrm{MPa})$ & \multicolumn{4}{c}{ Damage } \\
& & & $k$ parameters & $\mathrm{KIC}\left(\mathrm{MN} / \mathrm{m}^{3 / 2}\right)$ & $\lambda(\mathrm{kg} / \mathrm{J})$ \\
\hline 2530 & 40 & 0.22 & 2 & $2.33 \times 10^{24}$ & 7 & 0.92 \\
\hline
\end{tabular}

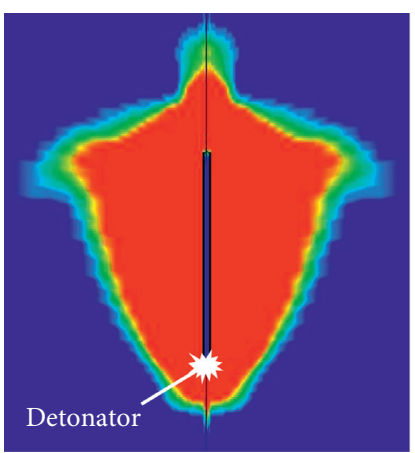

(a)

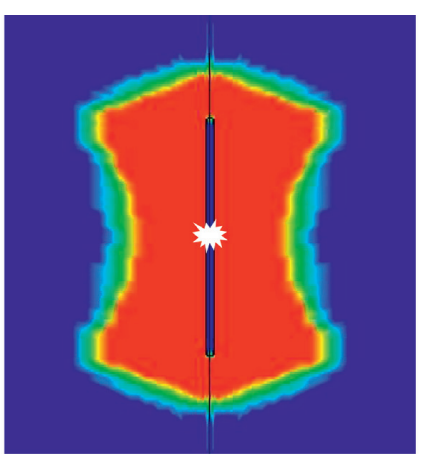

(b)

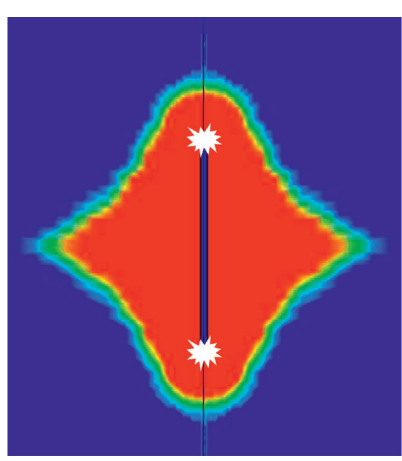

(c)

Fringe levels

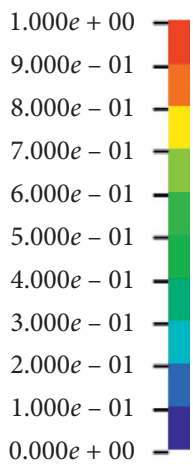

$0.000 e+00$ (b) Midpoint FIgURE 15: Blast-induced damage
detonator; (c) Two-end detonator.

(length $\times$ width $\times$ height), including 195520 elements and 202554 nodes. The simulation contains three blastholes, and the Burden $\times$ Spacing is $0.9 \mathrm{~m} \times 1.8 \mathrm{~m}$. The blastholes are all $5.0 \mathrm{~m}$ in depth and $90 \mathrm{~mm}$ in diameter. The charging length is $3.5 \mathrm{~m}$ and $70 \mathrm{~mm}$ in diameter. Except for the free surface, the nonreflecting boundaries were applied to the other surfaces of the model.

It needs to be pointed that the physical parameters of the rock mass at the top surface are different from those inside, because the parameter degradation would be unavoidably caused by the excavation damage from the last step or the surface relaxation. Thus, in this simulation, it is assumed that, within $1.5 \mathrm{~m}$ inside the top surface, the rock parameters gradually increase from outside to inside in a linear way, and beyond the range, the rock parameters remain the same.

4.2.2. Numerical Results. Figure 17 gives the damage distribution at the cross section I-I under differing detonator locations. Besides, Figure 18 plots the rock damage profile at the bottom zone of the blastholes. They indicate that the rock fragmentation effects are greatly affected by the detonator location. For the top detonator case, the damage preferentially develops to the hole bottom, so the damage profile looks like an inverted funnel (see Figure 17(a)). The downwards transmitting explosion energy under top detonator location is beneficial to the rock fragmentation at the hole bottom, but weakens the rock breakage at the top zone,

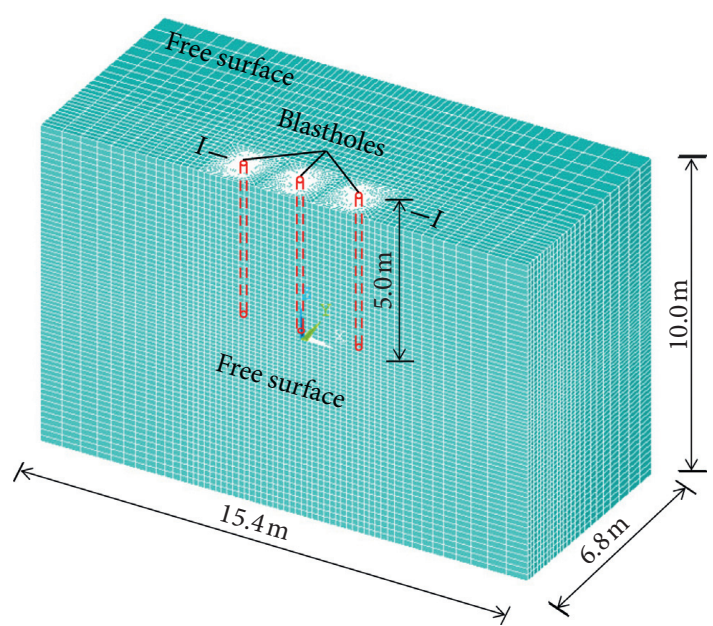

FIGURE 16: Numerical model of the multihole blasting.

and thereby causes some boulders. On the contrary, the damage profile under bottom detonator location is an erected funnel (see Figure 17(b)), as the damage preferentially develops to the top zone. Although the upwards transmitting explosion energy releases the problem of boulders, its poor function on the rock breakage at the hole bottom produces some rock toes. For the midpoint detonator location, the detonation waves simultaneously 


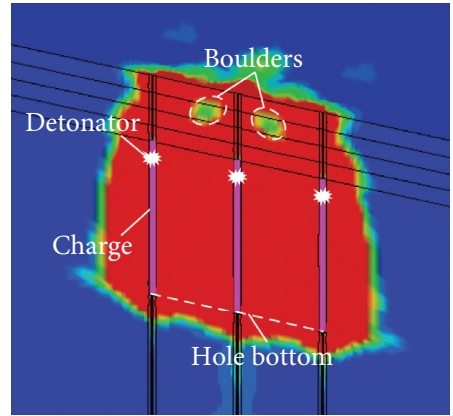

(a)

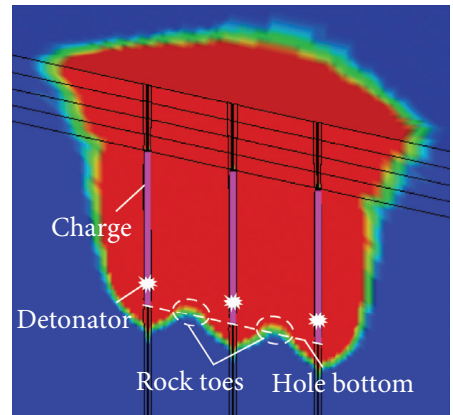

(b)

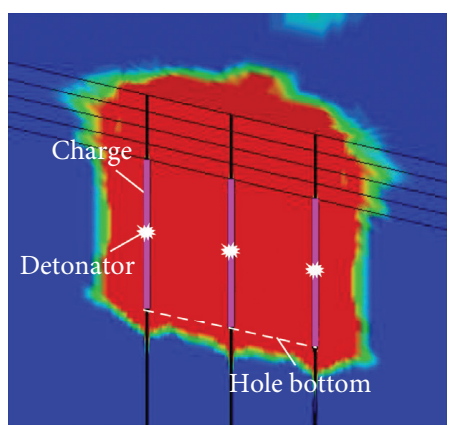

(c)
Fringe levels

$1.000 e+00$

$9.000 e-01-$

$8.000 e-01-$

$7.000 e-01$

$6.000 e-01$

$5.000 e-01-$

$4.000 e-01-$

$3.000 e-01-$

$2.000 e-01$

$1.000 e-01$

$0.000 e+00$

FIGURE 17: Blast-induced damage of the multihole blasting under differing detonator locations. (a) Top detonator; (b) bottom detonator; (c) midpoint detonator.

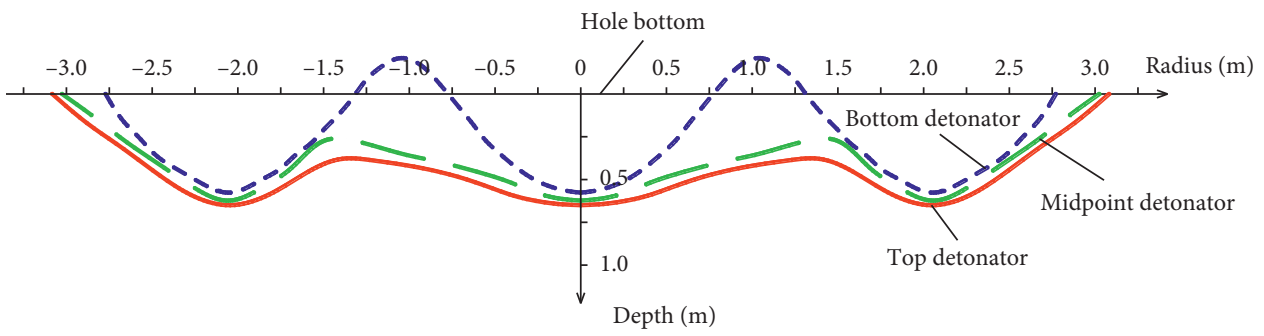

FIGURE 18: Blast-induced damage profile at the bottom zone of the blastholes.

propagate upwards and downwards, so the damage profile approaches to a cylinder with a slightly narrow zone at the middle section (see Figure 17(c)). In a word, as for the rock fragmentation, each detonator location has its merits and demerits. The simulation of the multihole blasting is valuable to enhance the understanding of the effect of detonator location on the rock fragmentation in bench blasting.

\section{Discussion on Improvement of the Detonator Location in Bench Blasting}

5.1. Problems Faced in Bench Blasting. The bench blasting is a key step of the whole mining production. The cost and efficiency of loading, hauling, crushing, and grinding operations are seriously affected by its outcome. However, boulders or oversize boulders are often produced in practice, as shown in Figure 19. These boulders not only affect the production efficiency but also increase the cost of secondary breakage and transportation. In addition, as shown in Figure 20, the rock toes, as are defined as the hard ridges above the bench floor, are also a confusing problem in bench blasting. The rock toes will become an obstacle to the movement of the backward rock mass in the next bench blasting and thereby produce more serious rock toes. Great efforts must be attached on the handling of rock toes, which will inevitably delay the blasting operations and increase the cost. Therefore, to ensure the downstream operations, much attention needs to be drawn on reducing the boulders and rock toes in bench blasting.
5.2. An Improved Scheme of the Detonator Location in Bench Blasting. Before this study, most researchers recommended that the detonator should be placed at the hole bottom to guarantee the rock fragmentation and throwing effects. They hold on the view that the bottom detonator can increase the usage ratio of explosion energy from the point of stress wave reflecting theory at the ground surface [14]. However, as was analyzed in the above sections, the detonator location plays an important role in the distribution of explosion energy and blast stress field. The detonator has the capacity of adjusting the spatial distribution of explosion energy transmitting to the surrounding rock mass. Thus, the bottom detonator is not always the best choice, and the detonator should be changed with the onsite conditions.

In fact, the boulders and rock toes are mainly caused by the insufficiency breakage of rock mass at the top or bottom of the blastholes. As for the rock fragmentation, the numerical simulation results indicate that each detonator location has its advantages and disadvantages (see Figure 17). Figure 21 presents an improved scheme of the detonator location in bench blasting, based on the understanding of traditional detonator locations. In this scheme, the explosive is divided into two parts by an inert barrier, and the length ratio of the upper to the lower explosive is about 2.0. The detonator within the lower $1 / 3$ length of the explosive is placed at the top section, so as to adjust the explosion energy transmitting to the hole bottom and reduce the rock toes. While the upper $2 / 3$ explosive is used to ensure the rock fragmentation and throwing effects, so the detonator is placed a little lower 


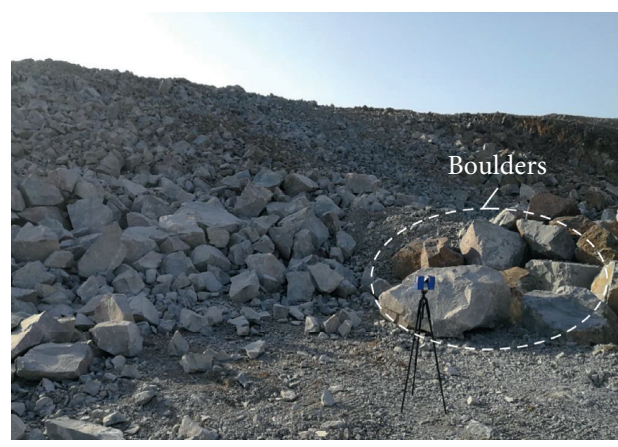

(a)

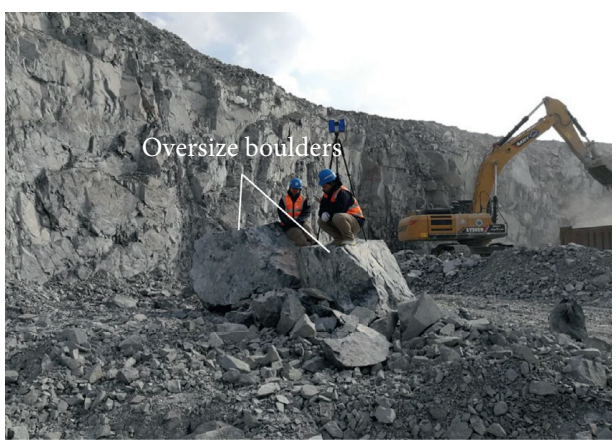

(b)

FiguRE 19: Illustration of the problem of boulders in bench blasting. (a) Boulders; (b) oversize boulder.

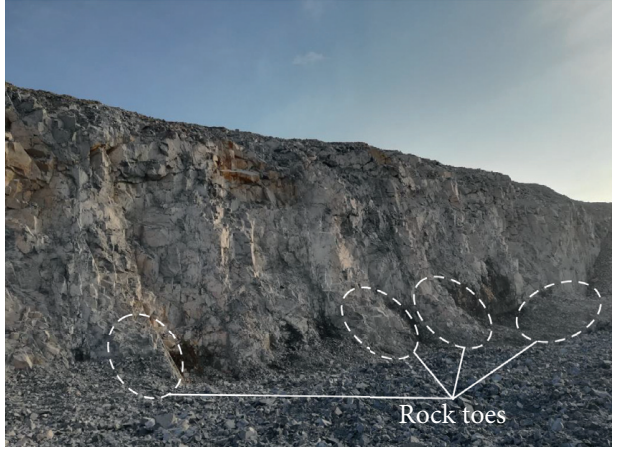

(a)

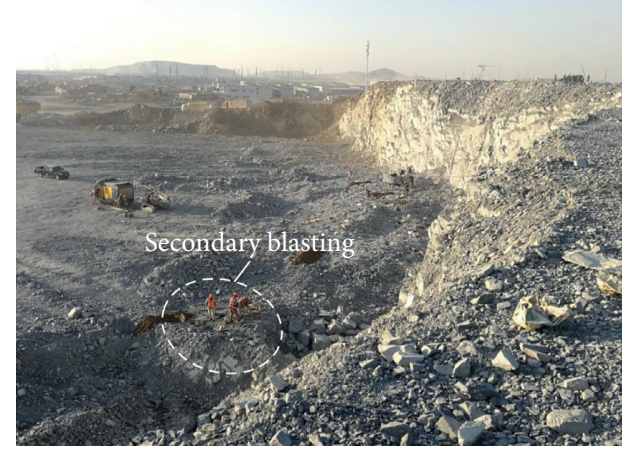

(b)

FIgURE 20: Illustration of the problem of rock toes in bench blasting. (a) Rock toes; (b) handling of rock toes by secondary blasting.

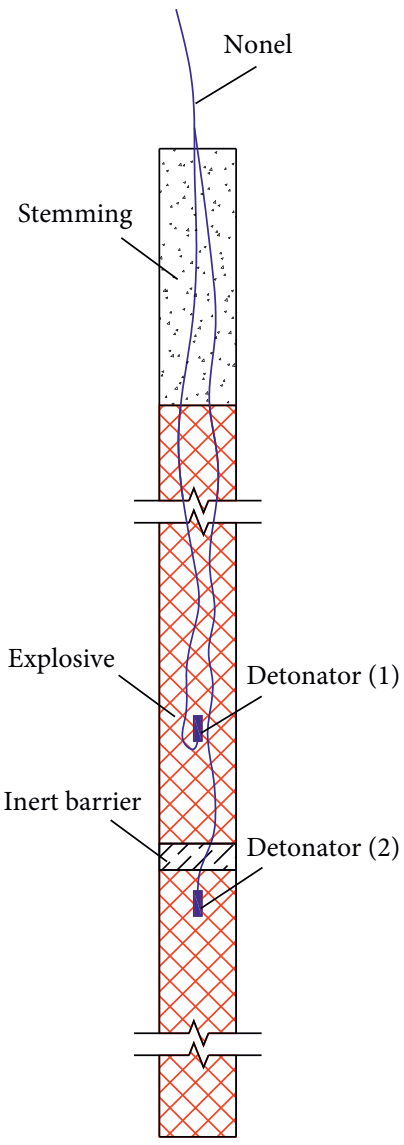

Figure 21: An improved scheme of the detonator location in bench blasting. 
than the middle section. The inert barrier here is used to prevent the energy concentration between the upper and lower detonators (see Figure 16(c)). The improved scheme comes from an idea of combining the merits of traditional detonator locations, so as to further cope with the boulders and rock toes. More onsite blasting experiments are still needed to verify and optimize this detonator location scheme.

Except for the detonator location, many other factors, such as the drill and blast parameters, the explosive properties, the space-to-burden ratio, and the onsite geological conditions, also greatly affect the outcome of bench blasting. Hence, the detonator location should be considered comprehensively with other influence factors. This paper mainly focuses on the effect of detonator location, so the detailed discussion on other factors is not included.

\section{Conclusions}

The mathematics and mechanics of the effect of detonator location was analyzed at first. Then, a field experiment as well as two numerical simulations was also conducted to display the effect of detonator location on blasting outcomes. At last, an improved scheme of the detonator location in bench blasting was proposed, according to the understanding of the effect of traditional detonator locations. Several valuable conclusions can be drawn as follows:

(1) The in-hole detonator has the capacity of adjusting the spatial distribution of explosion energy and blast stress in the surrounding rock mass. On the one hand, the energy distribution of a cylindrical charge is closely associated with the detonator location, and more energy is distributed to the forward direction of the detonation wave. On the other hand, due to the phase delay effect, the blast stress field of a cylindrical charge is not uniformly distributed but strengthened at the forward direction of the detonation wave either.

(2) The experimental results indicate that, for the vertical blasthole, the PPVs below the hole bottom under bottom detonator location are 21\% 59\% lower than those under top detonator location. The numerical simulations show that each detonator location has its merits and demerits in terms of the rock fragmentation effect.

(3) The traditional recommendation of the bottom detonator is not always right, and the detonator location should be changed with the onsite conditions. The optimized detonator location in bench blasting is available by properly combining the merits of traditional detonator locations.

\section{Data Availability}

The data used to support the findings of this study are available from the corresponding author upon request.

\section{Conflicts of Interest}

The authors declare that there are no conflicts of interest regarding the publication of this paper.

\section{Acknowledgments}

This work was supported by the Fundamental Research Funds for the Central Universities, CHD (no. 300102210123), the Visiting Scholar Fund of Key Laboratory of Rock Mechanics in Hydraulic Structural Engineering, Ministry of Education (no. RMHSE1903), Chinese National Natural Science Foundation (no. 51809016), and Chongqing Municipal Natural Science Foundation (no. cstc2019jcyjmsxmX0645). The authors wish to express their thanks to all supporters.

\section{References}

[1] D. S. Kim and M. K. McCarter, "Quantitative assessment of extrinsic damage in rock materials," Rock Mechanics and Rock Engineering, vol. 31, no. 1, pp. 43-62, 1998.

[2] J. Mosher, Crushing, Milling, and Grinding, "SME Mining Engineering Handbook", vol. 2, Society for Mining, Metallurgy,and Exploration, Englewood, CO, USA, 3rd edition, 2011.

[3] B. Ohadi, X. Sun, K. Esmaieli, and M. P. Consens, “Applied data analytics on blast-induced outcomes using multiyear blasting data from an operational open pit mine," in Proceeding of the 12th International Symposium on Rock Fragmentation by Blasting, pp. 395-405, Lulea, sweden, June 2018.

[4] H. Mansouril, F. Ouchterlony, H. Inanloo Arabi Shad, and A. Böhm, "Effect on comminution properties of blast preconditioned magnetic mortar," in Proceeding of the 12th International Symposium on Rock Fragmentation by Blasting, Luleå University of Technology, Lulea, Sweden, pp. 407-414, 2018.

[5] Z. Yang, W. Lu, Q. Gao, P. Yan, M. Chen, and H. Hu, "Back analysis and calculation of dynamic mechanical parameters of rock mass with measured blasting vibration signals," Mathematical Problems in Engineering, vol. 2018, Article ID 7297945, 11 pages, 2018.

[6] D. Gan, X. Yang, Y. Zhang, and X. Wei, "Stability analysis of underground multicavities in bench blasting vibration," Mathematical Problems in Engineering, vol. 2019, Article ID 4014761, 10 pages, 2019.

[7] Z. Leng, Q. Gao, W. Lu, G. Zhou, and Y. Hao, "Experimental and numerical investigation on rock fragmentation under combined blastholes with different diameters," in Proceeding of the 12th International Symposium on Rock Fragmentation by Blasting, pp. 509-525, Luleå, Sweden, 2018.

[8] W. A. Hustrulid, Blasting Principles for Open Pit Mining: Theoretical Foundations, Balkema, Rotterdam, Netherlands, 1999.

[9] F. Outchterlony, "The swebrec function: linking fragmentation by blasting and crushing," Mining Technology Journal, vol. 114, no. 1, pp. 29-44, 2005.

[10] J. K. Furtney, P. A. Cundall, and G. P. Chitombo, "Developments in numerical modeling of blast induced rock fragmentation: updates from the HSBM project," in Proceeding of the 9th International Symposium on Rock Fragmentation by Blasting, CRC Press, Boca Raton, FL, USA, pp. 13-17, September 2009. 
[11] M. Sazid and T. N. Singh, "Numerical assessment of spacingburden ratio to effective utilization of explosive energy," International Journal of Mining Science and Technology, vol. 25, no. 2, pp. 291-297, 2015.

[12] J. A. Sanchidrián and F. Ouchterlony, "A distribution-free description of fragmentation by blasting based on dimensional analysis," Rock Mechanics and Rock Engineering, vol. 50, no. 4, pp. 781-806, 2017.

[13] C. Knock and N. Davies, "Blast waves from cylindrical charges," Shock Waves, vol. 23, no. 4, pp. 337-343, 2013.

[14] Y. Long, M. Zhong, Q. Xie, X. Li, K. Song, and K. Liao, "Influence of initiation point position on fragmentation by blasting in iron ore," Rock Fragmentation by Blasting, vol. 10, pp. 111-116, 2012.

[15] Z. Zhang, "Increasing ore extraction by changing detonator positions in lkab malmberget mine," Fragblast, vol. 9, no. 1, pp. 29-46, 2005.

[16] I. A. Onederra, J. K. Furtney, E. Sellers, and S. Iverson, "Modelling blast induced damage from a fully coupled explosive charge," International Journal of Rock Mechanics and Mining Sciences, vol. 58, no. 58, pp. 73-84, 2013.

[17] L. Liu, M. Chen, W. Lu, Y. Hu, and Z. Leng, "Effect of the location of the detonation initiation point for bench blasting," Shock and Vibration, vol. 2015, Article ID 907310, 11 pages, 2015.

[18] Z. Leng, W. Lu, M. Chen, Y. Fan, P. Yan, and G. Wang, "Explosion energy transmission under side initiation and its effect on rock fragmentation," International Journal of Rock Mechanics and Mining Sciences, vol. 86, pp. 245-254, 2016.

[19] R. F. Favreau, "Generation of strain waves in rock by an explosion in a spherical cavity," Journal of Geophysical Research, vol. 74, no. 17, pp. 4267-4280, 1969.

[20] P. A. Heelan, "Radiation from a cylindrical source of finite length," Geophysics, vol. 18, no. 3, pp. 685-696, 1953.

[21] D. Jordan, "The stress wave from a finite, cylindrical explosive source," Indiana University Mathematics Journal, vol. 11, no. 4, pp. 503-551, 1962.

[22] A. M. Abo-Zena, "Radiation from a finite cylindrical explosive source," Geophysics, vol. 42, no. 7, pp. 1384-1393, 1977.

[23] J. E. White and R. L. Sengbush, "Shear waves from explosive sources," Geophysics, vol. 28, no. 6, pp. 1001-1019, 1963.

[24] D. Blair, "Seismic radiation from an explosive column," Geophysics, vol. 75, no. 1, pp. E55-E65, 2010.

[25] M. Gong and J. H. Li, "A research on stress field of column and strip shaped charge in different detonated points," Journal of University of Science and Technology Beijing, vol. 24, no. 3, pp. 248-253, 2002, in Chinese.

[26] F. D. R. Vanbrabant, E. P. Chacón, and L. A. Quiñones, "P and $S$ mach waves generated by the detonation of a cylindrical explosive charge ? experiments and simulations," Fragblast, vol. 6, no. 1, pp. 21-35, 2002.

[27] L. F. Triviño, B. Mohanty, and B. Milkereit, "Seismic waveforms from explosive sources located in boreholes and initiated in different directions," Journal of Applied Geophysics, vol. 87, no. 12, pp. 81-93, 2012.

[28] K.-W. Liu, X.-H. Li, X.-B. Li, Z.-H. Yao, Z.-X. Shu, and M.-H. Yuan, "Characteristics and mechanisms of strain waves generated in rock by cylindrical explosive charges," Journal of Central South University, vol. 23, no. 11, pp. 2951-2957, 2016.

[29] B. Zhang, Q. Zhang, and F. Huang, Detonation Physics, Weapon Industry Press, Beijing, China, 2001, in Chinese.

[30] H. Hu, W. Lu, P. Yan, M. Chen, Q. Gao, and Z. Yang, "A new horizontal rock dam foundation blasting technique with a shock-reflection device arranged at the bottom of vertical borehole," European Journal of Environmental and Civil Engineering, vol. 24, no. 4, pp. 481-499, 2017.

[31] H. Hu, W. Lu, P. Yan, M. Chen, and Q. Gao, "A vibrationisolating blast technique with shock-reflection device for dam foundation excavation in complicated geological conditions," Shock and Vibration, vol. 2018, Article ID 8029513, 11 pages, 2018.

[32] H. Li, X. Xiang, J. Li, J. Zhao, B. Liu, and Y. Liu, "Rock damage control in bedrock blasting excavation for a nuclear power plant," International Journal of Rock Mechanics and Mining Sciences, vol. 48, no. 2, pp. 210-218, 2011.

[33] W. Lu, Z. Leng, H. Hu, M. Chen, and G. Wang, "Experimental and numerical investigation of the effect of blast-generated free surfaces on blasting vibration," European Journal of Environmental and Civil Engineering, vol. 22, no. 11, pp. 1374-1398, 2018.

[34] W.-B. Lu, Y.-G. Hu, J.-H. Yang, M. Chen, and P. Yan, "Spatial distribution of excavation induced damage zone of high rock slope," International Journal of Rock Mechanics and Mining Sciences, vol. 64, no. 6, pp. 181-191, 2013.

[35] Y. Hu, W. Lu, M. Chen, P. Yan, and J. Yang, "Comparison of blast-induced damage between presplit and smooth blasting of high rock slope," Rock Mechanics and Rock Engineering, vol. 47, no. 4, pp. 1307-1320, 2014. 